\title{
REFLEXIVIDADE EM SAÚDE: INVESTIGAÇÃO FENOMENOLÓGICA DO PROCESSO REFLEXIVO PREVALENTE ENTRE OS FORMANDOS EM EDUCAÇÃO FÍSICA
}

\author{
Karina Tiemi Murata* \\ Cristiano Roque Antunes Barreira**
}

Recebido: 27 abr. 2011

Aprovado: 13 set. 2011

\begin{abstract}
* Bacharel em Ciências da Atividade Física pela Escola de Artes Ciências e Humanidades da Universidade de São Paulo. São Paulo, SP, Brasil. E-mail: katimuta@gmail.com.

** Doutor, Professor da Escola de Educação Física e Esportes de Ribeirão Preto, (EEFERP), da Universidade de São Paulo. São Paulo, SP, Brasil E-mail: crisroba@usp.br.
\end{abstract}

Resumo: O presente trabalho buscou identificar e compreender como se dão os processos reflexivos prevalentes na relação interpessoal constituída na atuação pré-profissional de formandos em um curso na área da educação física. Tendo em vista este objetivo, utilizou-se a fenomenologia como um método capaz de identificar o sentido das coisas dadas à consciência. Optou-se também pela utilização adaptada de um roteiro de supervisão para psicólogos do esporte por abordar amplamente os variados aspectos da experiência relacional em contexto de atendimento. Os resultados apontam para a prevalência do modo de pensamento mecanicista como plano de fundo de uma reflexividade causal e restrita durante a atuação pré-profissional destes formandos. Assim, uma atuação dirigida à reflexibilidade, possibilita uma abertura ao relacionamento interpessoal de maneira a incluir o sujeito a quem a prática se destina como agente do processo, e não como objeto de intervenção. O método fenomenológico pode auxiliar na manutenção e constante aprimoramento deste processo reflexivo, uma vez que permite compreender as dimensões de ordem existencial da atividade física.

Palavras-chave: Reflexividade. Fenomenologia. Educação Física.

\section{REFLEXIVITY IN HEALTH: PHENOMENOLOGICAL RESEARCH ON THE REFLECTIVE PROCESS PREVALENT AMONG GRADUATES IN PHYSICAL EDUCATION}

Abstract: This study sought to identify and understand how to give the reflective processes prevalent in interpersonal relationships formed in the pre-professional performance of graduates in a in physical education program. Toward this goal, we used phenomenology as a method capable of identifying the meaning of things given to consciousness. The choice was made for the use of a supervision script for sport psychologists because of its approach of widely varied aspects of relational experience in the context to address the widely varied aspects of human experience in context of care. The results indicate the prevalence of a mechanistic way of thinking as the background of a causal and restricted reflexivity during the pre-professional performance of these graduates. Thus, an action directed at reflexivity enables an opening to interpersonal relationship so as to include the subject to whom the practice is intended as an agent of the process and not as an object of intervention. The phenomenological method can assist in the maintenance and constant improvement of this reflective process, since it allows us to understand the existential dimensions of physical activity.

Key words: Reflexivity. Phenomenology. Physical Education. 


\section{INTRODUÇÃO}

A saúde como área de atuação profissional vem sendo amplamente discutida não somente entre os limites da profissão médica, mas também envolvendo profissionais que contribuem e compõem o atendimento em saúde, entre eles psicólogos, assistentes sociais, fisioterapeutas e educadores físicos, reconhecendo-se assim seu caráter multidisciplinar. Desta forma, a atuação em saúde vem sendo palco de diversas discussões ao longo dos últimos anos em virtude das reflexões e dos paradigmas levantados acerca do modo como essa temática é entendida e por sua vez aplicada por seus profissionais. Atualmente a demanda por profissionais na área da educação física vem aumentando, o que reflete no aumento de cursos em universidades públicas. As justificativas geralmente apontam para o maior número de doenças e fatores de risco causados pelo sedentarismo e obesidade aliados à vida moderna e o aumento da tecnologia disponível. Essa combinação se transforma numa justificativa preocupada e pautada numa questão de saúde pública, o que torna cada vez mais tangente a relação entre saúde e atividade física, principalmente em se tratando no nível primário da prevenção de fatores de risco. Valter Bracht (1999) discute a vinculação desta nova tendência, em direcionar a educação física para a promoção da saúde, a uma renovação/atualização da ênfase na busca da "aptidão física"/ higienismo, objetivo presente e que marcou as tendências originais da Educação Física no Brasil, como a tendência militarista e, sobretudo, a biomédica. Assim "essa proposta revitaliza a idéia de que a principal tarefa da EF é a educação para a saúde ou, em termos mais genéricos, a promoção da saúde.” (1999, p. 79). O ponto crítico pode ser aqui colocado como o uso da educação física para a educação de corpos saudáveis de forma mecânica e instrumental, tomando como base simplesmente as heranças higienistas da educação física, sem partir de discussões e reflexões acerca dos temas relacionados à saúde e do próprio ser humano em questão, uma vez que não se entenda a saúde dentro de um tema restritamente biológico. Sendo assim, é importante problematizar a atuação do profissional da atividade física, quando ela corre o risco de tornar-se unicamente prescritiva, pois tendo como objetivo, seja a saúde, seja bem-estar físico ou psicológico, dificilmente seria alcançado com a aplicação de um modelo de bem-estar/saúde externo ao próprio sujeito - aspecto este discutido mundialmente, como indica o trabalho francês de Gori e Del Volgo (2008). A ênfase na prescritividade pode impedir, assim, a comunicação verdadeira na relação humana dentro da atuação profissional, já que, conforme conclui o filósofo Hans-Georg Gadamer (2006) “a saúde não permite que valores padrões, 
transferidos ao caso singular com base em experiências médias, se imponham" (p. 113). Sua conclusão é fundamentada na ideia de que "aplicações de regras, com base em valores de medida, não é algo natural. As medições, seus padrões de medida e os procedimentos de medida servem-se de uma convenção, com a qual nos aproximamos das coisas e as submetemos à mensuração" (GADAMER, 2006, p. 113). Para o autor a saúde "se revela num tipo de bem-estar e, ainda mais, quando nos mostramos dispostos a empreendimentos, abertos ao conhecimento e podemos nos auto-esquecer” (p. 118).

Sendo assim é conveniente levantar um questionamento anterior a tudo isso: o que é saúde? Efetivamente, durante a prática profissional no campo da saúde, toda a complexidade relativa à discussão do conceito de saúde deveria ser reconduzida a seu solo primeiro, isto é, ao fato de que só existe saúde enquanto tal se esta estiver presente no sujeito em sua universalidade e singularidade histórica/cultural e é a partir desse sujeito que poderemos obter informações sobre o que ela é enquanto saúde vivida. Esse acesso só pode se dar caso o profissional esteja aberto e disposto a este tipo de atenção ao outro durante a atuação.

No que se refere à área da atividade física, o entendimento de uma saúde não restrita apenas aos parâmetros fisiológicos é de grande importância para reflexão. Porém, de modo geral, a Educação Física se volta para um conceito de saúde "que se fixa em dados estatísticos, que reduz o fenômeno a uma relação causal determinada biologicamente, que desconsidera a história da sociedade, e que tende a responsabilizar, única e exclusivamente, o indivíduo por sua condição de vida” (CARVALHO, 2007, p. 19).

Muitos estudos nesta área propõem uma relação causal entre atividade física e saúde, podendo ser esta entendida "à priori, como consequência de efeitos fisiológicos (mensuráveis quantitativamente) produzidos pela prática regular de atividade física” (BAGRICHEVSKY; ESTEVÃO, 2005, p. 66). Tal relação, pautada na tradição "médico-higienista, de reduzida ou inexistente reflexão acerca dos intervenientes sociais, econômicos, culturais e políticos na vida das pessoas, e equivocada simplificação do ato 'pedagógico"' (QUINT et al, 2005, p. 83), desconsidera uma séria de elementos constituintes do ser humano, pois "adota um olhar parcial/distorcido da realidade, que não leva em conta outros fatores contextuais relevantes aos quais as pessoas estão submetidas e que não podem ser dissociados de seus cotidianos” (BAGRICHEVSKY; ESTEVÃO, 2005, p. 66).

Entretanto, a visão predominante na grande maioria dos cursos que formam profissionais que atuam na área da saúde é constituída por uma compreensão 
do ser humano fundamentada em modelos biomédicos, o que acarreta, em geral, relações verticalizadas e prescritivas, já que é promovida pela restrição do relacionamento interpessoal. Estes modelos tem seu foco voltado para a doença em detrimento da pessoa e desconsideram a subjetividade e biografia do paciente, pois "não apenas os pacientes não estão envolvidos nas decisões sobre seus próprios cuidados, mas a informação fornecida de forma vertical e impositiva nem sempre é compreendida.” (TRAVERSO-YÉPEZ, 2001, p. 52).

Esta fragmentação é fundada historicamente na divisão da pessoa: seu corpo, cujo domínio técnico é de responsabilidade profissional, e sua alma, presente apenas enquanto intermediária moral, seja ela culpabilizada ou desculpabilizada pelo adoecer, eficiente ou deficiente para a intervenção no corpo. Enquanto intermediário eficiente, ou obediente, o sujeito deve receber o comando e aplicá-lo a fim de atingir o resultado almejado. A partir disso é possível perceber que a atuação profissional pode ser baseada não somente em bases teóricas e técnicas, mas partir também da valorização do conteúdo biográfico e expressão do que a própria pessoa atendida pode oferecer e da capacitação pessoal do profissional para apreender e explorar tal conteúdo vivido, ou seja, é possível que o profissional tenha uma abertura a esses conhecimentos, deixando-se entrar numa construção mútua de saberes. Considerar a pessoa existencialmente pode elucidar a importância de uma relação dialógica com o sujeito, pois é a partir desse tipo de relação que podem ser esclarecidas o que é, segundo a visão de mundo do próprio sujeito, aquilo que nos é evidenciado. Tais princípios também são compartilhados pelo educador brasileiro Paulo Freire (2006, p. 123), para quem

respeitar a leitura de mundo do educando significa tomá-la como ponto de partida para a compreensão do papel da curiosidade, de modo geral, e da humana, de modo especial, como um dos impulsos fundantes da produção do conhecimento.

$\mathrm{O}$ aspecto educativo importa uma vez que a atuação profissional em atividade física implica em ensinar, construir um conhecimento mutuamente com o sujeito a quem se destina.

Grande parte dos novos cursos de educação física propõe uma visão problematizadora das áreas de atuação dos futuros profissionais uma vez que se dedicam à melhoria da qualidade de vida e do desenvolvimento humano. Isso leva a questionamentos constantes em relação ao processo de ensino/aprendizagem desses novos cursos, uma vez que é preciso repensar as maneiras como 
o mesmo se dá e, consequentemente, como será difundido por seus futuros profissionais.

Nesse sentido, este trabalho se dedica a examinar os processos reflexivos protagonizados por alunos de um curso da área de educação física de uma universidade pública, em exercício pré-profissional, isto é, a partir de seus exercícios práticos em estágios curriculares de atuação. Trata-se de conhecer como os formandos do curso se percebem atuando, o que possibilita o acesso às presenças reflexivas prevalentes. Tipificar essas presenças reflexivas, não a partir de categorias prévias, mas a partir do modo como se manifestarem na coleta de dados, poderá fornecer um útil panorama acerca dos reflexos na atuação prática do aprendizado da graduação, bem como sinalizar eventuais direcionamentos para aperfeiçoar o aprendizado referente à dimensão interpessoal da atuação profissional, seja com o foco na saúde ou não.

Sendo assim, a reflexão a que se refere neste trabalho pode ser definida segundo Body e Fales (apud ANDERSON et al, 2004, p. 191) como “o processo de exame e exploração interna de uma questão de preocupação, desencadeada por uma experiência, que cria e clarifica significados em termos de si-mesmo (self) e resulta em uma modificação da perspectiva conceitual" (tradução própria). A prática reflexiva, portanto, consiste em processar uma abordagem para a experiência em que o sujeito da ação esteja aberto e questione, valendo-se também do cultivo de

um tempo e um espaço para, retrospectivamente, examinar a prática em detalhe. Eventualmente tais exames podem levar a sentimentos de desconforto e vulnerabilidade, mas se os sujeitos da prática reflexiva estão comprometidos em aperfeiçoar a prática, então pensamentos e emoções desafiadores podem conclusivamente habilitá-los a aprender a partir de suas próprias experiências e entender o contexto de sua prática. (ANDERSON et al, 2004 p. 192, tradução própria).

Diante disso, o objetivo desta pesquisa é identificar e compreender fenomenologicamente, através de relatos acerca de sua própria experiência, como se dão os processos reflexivos prevalentes na relação interpessoal constituída na atuação pré-profissional de formandos na área da educação física.

\section{MÉTODO}

Com vistas a esse propósito, foi bem vinda a utilização de um método que fosse capaz de identificar o sentido das coisas na sua relação com o ser huma- 
no, ou seja, foi viável neste caso a aplicação da fenomenologia, sendo ela um método que se propõe "a compreender qualquer tipo de experiência enquanto tal ao buscar as vivências constitutivas da percepção do próprio sujeito sem partir de pré teorias" (BARREIRA et al, 2008). Para alcançar essa experiência a fenomenologia parte da própria consciência do sujeito, sendo que "a consciência é sempre consciência de alguma coisa” (BARREIRA; MASSIMI, 2005, p. 6) e, portanto, "é nessa relação, definidora da consciência, que o pensamento de Husser ${ }^{1}$ identifica a via de acesso, ou melhor, a via constitutiva da realidade" (p. 6). Esse acesso pode ser favorecido e catalisado por meio do relato da experiência vivida do próprio sujeito capaz de emergir em certas orientações de entrevistas. Tendo em vista isso, torna-se necessário orientá-la em acordo com a "atitude fenomenológica que permite um posicionamento do entrevistador atento às experiências relatadas pelo entrevistado, isto é, explorando o fenômeno reciprocamente” (BARREIRA et al, 2008). Uma etapa fundamental no método fenomenológico é o retorno às coisas mesmas que consiste em "tomar a atitude natural e separá-la da coisa, isto é, separar tudo aquilo que 'contamina' a relação entre consciência e coisa investigada; tirar de cena juízos, pressupostos, preconceitos, crenças e teorias” (BARREIRA; MASSIMI, 2005, p. 6).

Partindo desta tarefa explicitada pela fenomenologia, buscou-se a apreensão das experiências vividas por meio do relato dos formandos em um curso da área da educação física ${ }^{2}$ a respeito da relação com o outro dentro da atuação pré-profissional estabelecida em estágios curriculares de atuação. Optou-se pela utilização da adaptação do Procedimento Estruturado de Reflexão proposto originalmente por Anderson et al (2004) como roteiro de supervisão para psicólogos do esporte. Este roteiro é dividido em cinco categorias e foi escolhido por abordar amplamente os variados aspectos da experiência relacional em contexto de atendimento, desde uma descrição de uma experiência marcante, até as avaliações do próprio desempenho, da eficácia do modo procedido, da intersubjetividade, às alternativas de conduta e lições tiradas do evento. As cinco categorias são: 1 . descrição da experiência de consulta; 2. reflexão; 3 . conseqüências das ações; 4. táticas alternativas e 5. aprendizado A intenção foi usá-lo para nortear o andamento das entrevistas possibilitando a coleta de depoimentos acerca de experiências práticas com uma ampla consideração pelos variados aspectos perceptivos da situação. Desta forma a questão disparadora solicitava que o entrevistado falasse sobre uma experiência marcante

1 Edmund Husserl foi o criador da fenomenologia (1859-1938).

2 Este curso é um dos criados recentemente em universidades públicas, com o currículo mais atento aos cuidados com a saúde. 
durante sua vivência pré-profissional. Este procedimento, portanto, torna o acesso à experiência reflexiva acerca da atuação do estagiário também um desenvolvimento dialógico, com possibilidades mais versáteis do ponto de vista fenomenológico, isto é, do processo significativo, de registro e análise do que seriam, por exemplo, o registro observacional etnográfico. Trataram-se, assim, de entrevistas semi-estruturadas que proporcionaram um material de análise oriundo de um auto-esclarecimento mútuo das vivências, visando definir as características percebidas nessas experiências de relacionamentos ocorridos nas atuações pré-profissionais.

No que se refere aos procedimentos, a amostra intencional foi delimitada por alunos que cursavam o último ano de um curso na área da educação física. Realizaram-se seis entrevistas obedecendo ao critério da saturação para determinar o encerramento das mesmas. Os alunos foram convidados a colaborar com a pesquisa concedendo entrevistas áudio-gravadas que foram transcritas na íntegra para posterior análise fenomenológica. Todos eles tiveram suas identidades resguardadas e somente foram entrevistados após assinarem um termo de consentimento livre e esclarecido, obedecendo aos cuidados éticos para este gênero de pesquisa.

\section{RESULTADOS}

Com o objetivo de compreender os processos reflexivos presentes na maneira como o formando ${ }^{3}$ em um curso da área da educação física pensa a sua atuação pré-profissional, as entrevistas foram analisadas baseadas no método fenomenológico, a fim de identificar, genericamente, tais processos e compreender como os mesmos estão presentes em seu dia-a-dia curricular durante a formação acadêmica desses profissionais.

Será possível perceber nos relatos abaixo a predominância de um pensamento baseado, em grande parte, na compreensão biológica de ser humano e como essa visão se expande para a compreensão da própria atuação profissional. Também será possível notar como a reflexividade ${ }^{4},-$ aqui tida como parte do

3 Em acordo com o que está na metodologia, o que se chama aqui de formando é aquele sujeito típico que pode ser descrito a partir das entrevistas com alguns alunos que se formaram no ano de 2008. Portanto esse caráter típico aponta para modos de reflexão predominantes e não exclusivos.

4 O Dicionário Histórico da Língua Francesa, Le Robert, informa que a palavra reflexivité aparece pela primeira vez em 1857, derivada de réflexif, sendo especialmente empregada em filosofia, em matemática e, nas ciências humanas, em psicologia. Portanto, a palavra em inglês é provavelmente um galicismo. Da maneira como é empregada no artigo tomado como referência, trata-se não apenas de um galicismo, mas do uso de um conceito cunhado para expressar um modo de pensar que se volta a si próprio a fim de problematizar seus pressupostos e fundamentos. Do ponto de vista gramático preciso, é uma neologia constituída por decalque, isto é, uma tradução literal do estrangeirismo em questão (Gramática Houaiss da Língua Portuguesa). 
processo de coleta e análise das entrevistas através do roteiro anteriormente discutido - propõe aos entrevistados a possibilidade de pensar sua própria atuação, contemplando de forma mais ou menos abrangente, questões que, em sua maioria, permaneciam adormecidas.

Observa-se no trecho abaixo da entrevista de S1 que a relação de causa e efeito fornecida pelos dados da avaliação física é o objeto de certa circunstância do relacionamento estagiário/usuário. A entrevistada questiona-se a respeito do imperativo cego, isto é, a respeito do fato de que a orientação à atividade física seja uma ordem cujas razões funcionais não sejam conhecidas pelo usuário - o que expressa consideração pela pessoa e pela importância da justificativa bem informada da prática, havendo clareza da estagiária quanto ao objetivo de sua atuação. Porém, quando se coloca a atenção ao fenômeno reflexivo apresentado pela entrevistada, evidencia-se o modo como a informação explicativa é trazida como mais um fator de uma ordem causal. Nessa ordem causal, aula, efeito e argumento unem-se para o alcance da finalidade pré-definida, a permanência do usuário na prática:

É, eu tinha como argumentar também nos dados (avaliação fisica), geralmente você chega lá e "ah, aumentou isso, aumento aquilo, aumentou aquilo outro e tal e o cara mandou vir fazer aula aeróbica, mandou fazer trabalho aeróbico", mas a pessoa muitas vezes não sabe porque está fazendo, então na própria sala de avaliação eu já explicava tudo isso, assim, que eu acho que era um fator que também determinava que os alunos fossem na aula e tivessem uma justificativa pra continuar indo. (S1) [grifo nosso]

A justificativa trazida pela entrevistada para o maior contato com as alunas também entra na mesma ordem de raciocínio para o alcance da finalidade prédefinida:

a gente tem milhares de motivos pra parar de fazer exercício, então primeiro assim, motivar que elas continuassem, [...] que elas tivessem compromisso comigo de estar indo, fazendo exercício e, também, era interessante por causa da academia, a academia não ia se interessar em ter uma aula vazia, então tinha que cumprir a freqüência dos alunos. (S1)

que eu tentava fazer era ter um grupo fechado [...] no periodo da manhã é um pouco mais complicado, principalmente o horário que eu tinha, então tentava ter um maior contato possivel com elas [...]. (S1)

Desse modo, a linha de raciocínio seguida toma o relacionamento tendo por base fatores objetivos, geralmente partindo de conceitos técnicos externos 
à pessoa e sua experiência biográfica, isto é, colocados como valores abstratos e universais - o quanto fazer atividade física é importante -, cujo aspecto informativo bastaria para garantir a aderência. $\mathrm{O}$ relato mostra a unilateralidade da atuação, em que os motivos e argumentos para a prática do exercício são provenientes do estagiário e recebidos pelo usuário. Nesse sentido, o fator informação, ainda que essencialmente qualitativo, é pensado pelo registro da quantidade, os "milhares de motivos". Mesmo que não seja algo de fato quantificado, observa-se como a informação é implicitamente tida como fator calculável, cuja quantidade adequada evitaria que as usuárias parassem. No sentido inverso, não parar a prática possivelmente seria o indicador objetivo de que a quantidade ou qualidade de informação foi suficiente:

acho que eu não exerci tanto o papel de mostrar pra elas o quanto a atividade fisica era importante, porque dessas que pararam algumas não estão fazendo nada hoje. E o que eu tentei demonstrar era que era bom fazer exercício sempre, continuar sempre, e algumas acabaram parando. (S1) [grifo nosso]

Evidencia-se, então, que o pensamento conclui-se aqui não havendo uma busca de outros caminhos que levem a outras possibilidades de atuação a partir desta experiência vivida, mas a simples insistência na mesma conduta explicativa.

mesmo eu falando: "não, fica, é importante", falava dos motivos, tal, muitas não queriam fazer e talvez eu pudesse ter motivado um pouco mais, ter explicado melhor ou ter motivado elas a continuar, a ficar mais meia hora pra fazer essa aula [...]. Eu expliquei, o quão importante é o alongamento e tal, os motivos, que com o passar da idade elas vão perdendo amplitude que é importante manter, tanto pra fazer as atividades diárias delas, como melhora na eficácia do desempenho eu explicava tudo isso. (S1)

Assim, embora se constate que algo não funcionou, já que nem todas as alunas continuaram, não há um questionamento do que seja o próprio papel da estagiária - conforme se nota no penúltimo relato citado, "eu não exerci tanto o papel" -, há tão somente a constatação de que determinado papel não foi bem exercido, eventualmente, não na quantidade correta.

Em alguns casos não se percebem alternativas que não sejam contrárias às consideradas adequadas, ou seja, àquela realizada. Quando questionados a respeito de qual outra atitude poderiam ter tomado diante da mesma situação, encontra-se em alguns relatos a ausência de consideração por outra forma de agir e um dualismo entre o que é bom e o que não é, ou seja, qual seria a alter- 
nativa contrária à que tomaram. Nos relatos identificados como S1, S5 e S6 não se visualiza, entretanto, qual outro tipo de atitude poderia ser tomada mesmo dentro daquilo que se considera uma boa maneira de lidar com a situação. As alternativas se restringem àquilo que foi feito de forma programada. Nesse caso, pode-se ver como ter um conteúdo ou uma atitude pré-determinada assumidos como finalidade primeira e última, isto é, primordial e inquestionável, dificulta que o sujeito se coloque presente na própria atuação e impede que ele vá além na reflexão acerca de sua própria atuação, mesmo quando isso é feito retrospectivamente, como é o caso nas entrevistas. No trecho de S1, quando questionada se, além das já descritas, teria outras possibilidades de atuação, a pessoa relata ter feito o máximo possível para diversificar as aulas e tornálas mais atraentes pautando sua resposta em uma grade de possibilidades de atuação já conhecidas.

não que eu tenha feito tudo mas, é porque assim, eu tentava diversificar as aulas o máximo possível, então assim a aula de localizada nunca era só uma aula de localizada, então assim muitas vezes tinham atividades recreativas, que trabalhava, sei lá, membros inferiores, mas de um modo diferente do que pegar o pesinho e ficar levantando, então eu fazia outros tipos de atividade, eu acho que já era um diferencial legal (S1)

Nos relatos de S6, verifica-se a dualidade no momento em que é questionada a respeito de outra atitude que poderia ter tomado diante da mesma situação e sua visualização se apresenta de modo imediatamente contrário àquela tomada por ela, isto é, uma atitude indiferente, contrária a toda atenção dirigida à aluna durante o tempo de estágio.

Podia ter sido indiferente, poderia ter dado aula normalmente, sem me preocupar em especial com ela e nem com nenhum outro aluno. Chegar lá no clube, dar a minha aula que é das sete às oito e acabou a aula entrar de novo pra sala e esperar a próxima aula. (S6)

E continua dizendo que esse tipo de atuação levaria às piores conseqüências:

Talvez a aluna não voltasse mais, ficasse traumatizada e não quisesse mais praticar atividade fisica, que pode acontecer, e acho que essa seria a pior conseqüência, ou então não querer ter aula comigo, querer ter aula com outro professor em outro horário, em outro lugar, essas conseqüências assim. (S6) 
Este outro relato exemplifica o mesmo dualismo e mostra o que seria o errado e condenável, que seria agir de maneira "contrária" à sua atuação:

O que eu vejo é a maneira autoritária que eu vejo que a maioria faz, é chegar pros caras e: "Cala a boca, isso aqui é um time, engole, cada um engole seu lado pessoal se não for pra ajudar o time fica todo mundo quieto." (S5)

E então a conseqüência seria: "Você diminui, você tem desistência né?” (S5) A reflexão a respeito do ocorrido se limita aos elementos que o profissional possui disponíveis enquanto experiências e aprendizado a respeito de sua própria atuação, seja em estágios, seja no próprio conteúdo de sala de aula. Desta forma, o pensamento se conclui quando o estagiário não encontra mais elementos que o forcem a ir além naquela situação, como pode ser percebido no relato acima. Essa restrição do raciocínio, enquanto consequências e possibilidades, diante de situações, promove uma lacuna na reflexão quando colocado diante de novos problemas e questões a serem resolvidas: o que é “certo” será repetidamente aplicado, o contrário será passível de ajuizamento negativo. O que baseia essas conceituações entre o certo e o errado parece não ter consistência enquanto produto de uma reflexão própria do estagiário, já que, embora o questionário utilizado nas entrevistas da pesquisa seja reflexivo, isto é, faça perguntas que demandam a reflexão, as respostas para o que é correto não chegam aos fundamentos que justificam as condutas, mas apenas a justificativas dadas como prontas, sem tentativa de explicitação de suas razões. A tendência é apenas a de elencar as alternativas de modo estereotipado e marcar a opção por uma.

Ainda dentro dessa visão linear, a própria relação estagiário/aluno assume uma posição impessoal. Uma vez que é a saúde do sujeito e não o próprio sujeito que está em pauta, essa impessoalidade do estagiário não permite que os sentidos da prática sejam explorados. A atividade física se direciona à saúde e não o estagiário ao sujeito. Sua base encontra-se alicerçada em conhecimentos apreendidos, porém pouco confrontados, resultando em um afastamento de si, da subjetividade da própria pessoa no contexto de atuação profissional. O destaque para esse elemento, isto é, para a minimização do auto-questionamento, diz respeito ao que o próprio conceito de prática reflexiva solicita, pois o mesmo envolve o questionamento interior. O que há de subjetivo é tratado de modo objetivo. As metas são baseadas no que há de pré-definido e não na abertura à subjetividade, alheia ao processo. Esse modo de atuação muitas vezes não é problematizado por seus protagonistas. 
No relato abaixo, pode-se destacar que apesar da aluna atendida trazer informações importantes relacionadas aos seus sentimentos, a estagiária encerra seu pensamento nas informações condizentes à sua atuação enquanto zeladora de um corpo saudável, desta forma, não permitiu que sua atenção fosse direcionada a esse aspecto importante valorizado pela própria cliente. O pensamento que se conclui baseado em informações, apenas buscou transferir a finalidade estética para outros valores, ou seja, os benefícios para a saúde, desviando-se do elemento subjetivo trazido pela aluna.

a pessoa chega assim, "ah, to me sentindo gorda" e eu "é....então....” [...] Então assim, desde o início eu tentei focar muito nisso tanto pra minhas alunas, tanto no tipo "ah vocês estão fazendo atividade aqui mas, vocês estão emagrecendo, como sei lá a maioria quer, mas vocês estão melhorando, sei lá, estão evitando é.... vamos supor... estão ajudando a ter uma prevenção contra alguns tipos de doença”. (S1)

Se estes resultados não focam precisamente o curso, mas o processo reflexivo prevalente de estagiários deste curso, deve-se, contudo, observar que alguns sujeitos entrevistados levantam suas próprias reflexões ao constatar a continuidade entre um modo de aplicar o conhecimento e um modo de ensinar esse conhecimento com base no que se viveu durante a graduação. Esse questionamento traz ao mesmo tempo um elogio à técnica aprendida e uma crítica ao modo como essa mesma técnica, percebida como intensamente valorizada e imposta, conduz a uma visão reducionista da atividade física como algo biológico, reducionismo de uma visão complexa de ser humano a uma visão impessoal.

É uma coisa que eu questiono muito aqui no curso da gente até, porque, assim, o pessoal força fisiologia, força fisiologia, que: "Olhem pro ratinho, vejam o que acontece com o ratinho e comparem. "Então tem horas que você corre o risco de tratar as pessoas [...] como se fossem ratos, entendeu? E eu acho que isso não é o principal [...]. Então eu acho que o conhecimento técnico pode ser uma base pra técnica assim bem, bem, bem comum a todos os trabalhos, mas o que vai dar o diferencial é o conhecimento humano. (S3)

Essa atenção ao humano e principalmente a abertura ao diálogo, começa a ser evidenciada nas entrevistas, em geral, a partir do momento em que foi solicitada a reflexão acerca da sua atitude profissional. Tirar o foco da causalidade permite que a pessoa vá além neste outro modo de pensar, que pode incluir as ações passadas de forma reflexiva e complexa, criando, então, uma nova visão dentro da atuação. Esse processo reflexivo, por vezes, é interrompido pelo ra- 
ciocínio causal o que restringe a margem das possibilidades de entendimento da situação e dos elementos envolvidos, simplificando desta forma elementos tão complexos quanto preciosos para a relação intersubjetiva destacada nos relatos.

As passagens abaixo do relato de S3 apresentam uma série de questionamentos a si mesmo acerca do que seria a atitude profissional. Para ele, esta é assumida como impessoal e não aberta ao outro, mesmo que não se saiba 0 fundamento desta concepção. Seu conflito é gerado justamente quando se dá conta de que esse tipo de atitude não aberta ao outro seria negativa para sua própria carreira profissional. Esse "se dar conta" o faz pensar sobre o tipo de relacionamento que estabelece com seu atual cliente/atleta e que se tornou uma amizade. O longo trecho se justifica por selecionar um movimento reflexivo com potenciais para transformar, pelas evidências da experiência interpessoal vivida, a reflexão prevalente que é marcada pela interrupção do tipo de raciocínio causal, externo à experiência:

Eu tentei me policiar em relação a isso também, pensei: "tem que ser profissional, profissional, profissional". E amizade não pode, tal; assim, o vínculo não pode ter muito, eu sempre procurei não deixar isso, mesmo porque fica mais fácil pra você falar um não, né? Mas eu percebi que foi ao contrário com ele, eu to vivenciando ainda, né? Acho que quando tem esse grau de amizade, você tem confiança né? Ai o pessoal te escuta mais também. Isso eu to achando um contra senso, mas realmente, a partir do momento que você é menos profissional, você é mais profissional. (S3)

Uma coisa que bloquearia essa abertura (ao outro) é eu ter essa mentalidade de que, não sei de onde vem isso também, de que o profissional tem que ser frio, isso é uma coisa que foi aprendida, não sei, foi embutido isso em mim, mas tinha essa concepção de que, ainda tenho inclusive digo: "Profissional é sinônimo de não ser legal." [...] eu tenho essa imagem de ser profissional, isso provavelmente, fechou muitas amizades, ou coleguismos [...] eu acho que você fazer um círculo de amizade, de contato, ter um bom convívio [...] acho que isso te abre portas depois, né? Então, eu acho que é uma coisa negativa - falando com você eu to percebendo isso agora também - é o que? A partir do momento que eu quero ser profissional, ser frio, você forçar isso, isso pode estar me fechando portas lá na frente, né? Tanto é o, vamos tomar, por exemplo, o atleta Luciano, de repente, um momento, no relacionamento com ele, de aluno e professor, treinador, o que seja, eu tava fechado, será que era melhor o treino assim? Será que não era? Não sei. Mas está sendo mais legal agora, disso eu posso ter certeza. (S3)

Durante o fechamento da entrevista a ideia foi ir ao encontro da seguinte reflexão: considerando as experiências passadas e a atuação futura, que sentido daria para essa reflexão proposta durante a entrevista? Em alguns casos notou-se um indício de direcionamento a uma relação mais atenta ao outro. Essa atenção 
é caracterizada por uma preocupação direcionada não somente à melhora da saúde ou rendimento, tidos como um componente biológico do ser humano, mas por elucidações acerca do que seria uma atuação mais aberta e disposta à troca intersubjetiva e não apenas baseada em recomendações impositivas que visam melhorar a saúde e o rendimento de forma isolada.

A finalidade pode continuar sendo a mesma, com a mesma ausência de reflexividade que clarificaria o que se objetiva, porém percebe-se que a experiência pode colocá-los diante de outra forma de abordar a realidade, diante da complexidade da pessoa atendida, do estagiário e do relacionamento interpessoal ali situado. Isto permite ser um ponto de partida para pensar a atuação de acordo com o outro, com as vivências, experiências da realidade interpessoal e que simplesmente a aplicação de um conhecimento técnico é insuficiente, que existe algo de anterior permeando o relacionamento humano, como confiança, responsabilidade, sentimentos, pessoalidade, situação/contexto, conversação e atitude. Nos relatos abaixo de S6 e S2, percebe-se uma reflexão que foge um pouco do ciclo causa/efeito e atinge sua própria atuação e o que dessa experiência ficou como aprendizado. S6 relata, ao final da entrevista, a importância de uma atuação atenta ao outro considerando toda a complexidade dos sentimentos e emoções, que podem vir à tona durante este tipo de relação profissional, e não restringir-se aos componentes técnicos da mesma. No caso de S2, a retomada da situação de conflito permitiu um reposicionamento a respeito de uma ação inicialmente dada como certa, embora pouco refletida - mostrando que a reflexividade demanda o investimento de tempo, de questionamento, de suspensão crítica da atividade assumida para haver um distanciamento capaz de fazê-la pensável. Este tempo - mesmo que insuficiente para mudar efetivamente o modo de refletir - foi promovido nas entrevistas:

É um papel, pra mim é uma responsabilidade porque a pessoa está ali confiando em você, então a gente tem que lidar o melhor possível com ela, o que você vai falar, acho que é uma responsabilidade muito grande da gente, dos professores de lá, de nós. [...] Porque você não está lidando com um computador, você está lidando com uma pessoa que tem sentimentos, uma palavra que você fala pode acabar magoando essa pessoa, então acho que a gente tem que pensar a pessoa como um ser humano e não como o número 144, a gente tem que pensar que é uma pessoa. (S6)

É talvez eu teria colocado antes os motivos do que eu coloquei só na reunião, né? Apesar de, quando das vezes que eu fui em novembro, dezembro, eu já tinha colocado isso, né? Pra todas elas, que eu conversei, que eu tava ali pra integrar, pra ser mais um, estar com ela, poder trabalhar... Então ela já sabia disso, eu 
poderia ter enfatizado, né? Pra ela mais uma vez.... É dificil..... A situação não volta (pausa) fica uma lição pras próximas, de você antes de tomar uma atitude, fica a lição de você refletir um pouco antes de tomar uma outra, né? Pensar bastante pra tomar uma outra, se for uma ocasião de você conversar, vai e conversa, se for a situação de você jogar direto pra gerente de novo, é uma questão de reflexão né? Depende da situação. (S2)

Embora a solicitação desse processo reflexivo seja parte da entrevista, é possível que o mesmo seja um recurso do próprio sujeito, ou seja, que o próprio sujeito o tenha como parte de sua atuação. Isso pode ser evidenciado nos relatos de $\mathrm{S} 4$, através dos quais foi possível identificar os elementos que contribuíram, ao longo de sua experiência e formação profissional, para a construção deste modo reflexivo de pensar a própria atuação. Neste relato S4 discute a utilização da dança ${ }^{5}$ como recurso terapêutico e se posiciona a favor de um aprofundamento sobre os elementos que a constituem para que a dança não se restrinja à aplicação de uma técnica:

[...] a dança como recurso terapêutico, mas sem perder o que é essencial na dança, [...] não simplesmente elaborar um método em que: "Agora vamos aplicar a dança de salão como terapia para... " Como ferramenta, não. Não é isso. Porque senão seria mais um técnica, mais uma técnica, mas tentar preservar o que é essencial na dança. Acho que daí vem a importância da questão da iniciação científica [...] de buscar isso. O que é essencial da experiência de dançar? O que que o dançar proporciona à pessoa, quando a pessoa dança o que ela de fato vive? Porque aí, em cima disso, eu posso repensar a minha atuação de como propiciar e potencializar essas vivências. (S4)

No relato abaixo, $\mathrm{S} 4$ destaca como suas experiências passadas com a dança, principalmente as negativas, também contribuíram para o modo como atualmente pensa sua atuação enquanto professora. É possível identificar o caminho da reflexão seguido por ela, que leva em conta sua própria vivência no contexto de aula, tanto como aluna quanto como professora, o que a faz questionar sobre o que aquele espaço da aula representa pro aluno e qual a atenção a ser dada a este aspecto pelo professor.

desde que eu comecei a dançar [...] tive experiências muito boas e [...] muito ruins, com diversos professores, então eu sempre me questionava: "Gente, como? A dança, algo que é tão prazeroso, que é tão bom que é tão gostoso, porque que tem que ser uma tortura? [...] eu falava: "Gente, como pode? As pessoas que procuram

5 A entrevistada S4 tem também formação em dança e durante a entrevista refere-se à sua experiência num estágio em que ministrava aulas de dança de salão. 
uma escola de dança, uma aula de dança, porque essas pessoas procuram uma aula de dança?" Muitos procuram porque [...] pra muitos é o único momento do dia, às vezes, da semana, que ela pode desconectar do mundo e fazer algo sem a pretensão de ser avaliada [...] ai vem alguém e fica ali na pessoa: "Não, não é assim, vocês está fazendo errado." Sabe, quer homogeneizar a turma. Ah não, não sei, acho que não pode ser dessa forma, ai que eu comecei a pensar, né? [...] como conduzir a aula de uma forma diferente, como realmente dar condições pras pessoas viverem aquele espaço de uma forma diferente, da forma que, claro, respeitando o objetivo de cada um. (S4)

Esse caminho reflexivo remete ao questionamento da atuação do estagiário e vai além, traz reflexões a respeito de si mesmo enquanto profissional, e também de forma mais ampla, rompendo o espaço do profissional, chegando à sua totalidade enquanto pessoa que atua, que vive e que tem o seu lugar mundo, isso pode ser visto nos relatos de S4 e S6 apresentados a seguir:

eu acho que cresci um pouquinho mais como pessoa, como profissional. Depois de todas as experiências que eu tive no estágio, acho que hoje eu vejo as coisas de uma outra forma. Então acho que essa foi a principal consequência, amadurecimento [...] de refletir realmente sobre qual é o meu papel no mundo, que éo papel da sua profissão diante da sociedade, ainda mais a nossa profissão que não é tão reconhecida. (S6)

Eu tenho o meu lugar no mundo é... Não é a função, vou falar: "A minha função no mundo é essa." Mas, um lugar mesmo sabe? Você ocupa esse espaço e a sua atividade, o que você desenvolve, ela (pausa) é importante pra outras pessoas, ela é importante não só pras outras pessoas, mas pra você mesmo. (S4)

Diante do caminho percorrido pelos resultados apresentados, nota-se que os processos reflexivos que se destacam inicialmente nesta pesquisa apontam para um modo mecanicista de se pensar a e na atuação. Esse modo reduz a compreensão a elementos previsíveis, uma vez que lê a realidade por meio de uma causalidade determinada, expressa e aplicada pelo cálculo. Tira-se de cena aquilo que não é passível de quantificação, ou seja, a subjetividade. Entretanto, é importante ressaltar que esse modo de pensar já caracteriza uma subjetividade, subjetividade esta disposta ao modo como o pensamento mecanicista é constituído. Desta forma, a fragmentação no modo de se pensar o homem resulta numa compreensão igualmente calculável e linear, isto é, o entendimento fica restrito às relações causais teoricamente previsíveis. Essa causalidade pode estar presente no entendimento da relação entre atividade física e saúde por profissionais da área, o que pode resultar, portanto, numa atuação pouco 
aberta a questionamentos e consequentemente distante de possíveis mudanças de comportamento na atuação.

A insuficiência causada por esta restrição no modo de pensar como as coisas se dão parece não ser tão visível, uma vez que o objetivismo, - entendido aqui como um raciocínio fechado, no qual o objetivo proposto é previamente estabelecido e conclusivo em si, portanto, os caminhos para se alcançar o objetivo já estão delineados e o raciocínio então se limita a essa circunstância - dá a impressão de que a relação causal é satisfatória para a reflexão se concluir e, além disso, se sugere ou se crê como sendo a única articulação cientificamente legítima. Seguir o objetivo proposto com passos previamente estabelecidos e legitimados pela ciência gera certa segurança, uma vez que a técnica tem sua comprovação efetivada: essa segurança é um dos aspectos subjetivos implícitos no uso do mecanicismo.

\section{DISCUSSÃO}

Tendo em vista os resultados apresentados, essa seção se dedica a discutir as questões centrais que permeiam o modo de pensamento prevalente entre $o$ grupo de entrevistados.

Diante das ações dirigidas pelo pensamento mecanicista, surge uma questão: Qual é a consequência desta atuação orientada pela técnica e pelo objetivismo, desvinculada de uma reflexividade profunda acerca do que a constitui? Podemos considerar diversos pontos nesta questão.

O pensamento mecanicista ${ }^{6}$, que rompeu com a compreensão de unidade do ser humano, vale-se de estratégias que buscam o entendimento do homem, enquanto elemento de quantificação, avaliação e legitimação da ciência como fonte de conhecimento fiel à realidade. Pode a técnica, a mensuração, a objetivação e o experimento, por si mesmos, compreenderem o ser humano como um todo? Pode a subjetividade ser alheia a este processo de entendimento? Nesse sentido, considerar o ser humano não como uma junção de partes, mas como uma unidade indissociável, é colocar, de fato, em pauta o sujeito. Aquele que realiza ações, pensa, deseja, cria. Não pautar o pensamento apenas naquele sujeito reificado que, seguindo o modelo de funcionamento das leis da natureza, repete, que é submetido, que é naturalmente manipulável ou sujeito à manipulação pela combinatória de fatores corretos cientificamente determinados.

6 O pensamento mecanicista se resolve pela "crença no fato de que todos os aspectos dos organismos vivos podem ser entendidos se reduzidos aos seus menores constituintes, e estudando-se os mecanismos através dos quais eles interagem" (CAPRA, 1995, p. 96). 
Pensar o ser humano é colocar em evidência as questões éticas de sua existência. Esse tipo de análise do homem parte de princípios complexos, da própria complexidade do ser humano. Entendê-la e não reduzi-la de modo simplificador é considerar o sujeito integralmente. A especialização entende o homem de maneira mutilada, desconexa, ausente do sentido de todo. Edgar Morin (2006) coloca o pensamento simplificador como a maneira encontrada para remediar a disjunção entre o sujeito pensante (ego cogitans) e a coisa entendida (res extensa), formulada por Descartes no século XVII. Este paradigma

rareando as comunicações entre o conhecimento científico e a reflexão filosófica, devia finalmente privar a ciência de qualquer possibilidade de ela conhecer a si própria, de refletir sobre si própria, e mesmo de se conceber cientificamente (MORIN, 2006, p. 11).

A maneira então encontrada foi a redução do "complexo ao simples (redução do biológico ao físico, do humano ao biológico)” (MORIN, 2006, p. 12). A especialização, portanto procurou desfazer a complexidade da realidade, correndo o risco de "fazer crer que o corte arbitrário operado no real era o próprio real" (p. 12). Pensando no âmbito da Educação Física, é possível identificar esse paradigma como sendo norteador de alguns modos de pensamentos que reduzem o homem a corpo fisiológico e mecânico, desconsiderando sua identidade. Os modos de pensamento pautados, em sua maioria, no modo causal constituem uma visão de corpo reduzida a aspectos predominantemente biológicos e, quando dirigidos à psicologia e às relações sociais, são excluídas a subjetividade e suas implicações e problematizações. Portanto, não só a compreensão do corpo é reduzida, mas a compreensão do próprio ser humano. O que há é um rompimento, uma divisão do homem enquanto conhecimento, as “partes” são estudadas conforme a sua especificidade e de acordo com o que é passível de cálculo e mensuração e como descreve Carvalho (2006, p. 155):

À medida que a educação física prioriza a dimensão física e biológica no que se refere ao corpo, ela o parte, o decompõe e ele perde a sua potência ainda que a justificativa da opção recaia no discurso da ciência”.

Em acordo com isso, a dimensão humana não é respeitada em sua integridade no que se refere à formação de profissionais na área de atividade física, uma vez que a atividade física é tida como instrumento para promover, quase que 
exclusivamente, alterações e modificações no corpo, compreendido biologicamente. Ainda neste processo de atuação em educação física situada na área da saúde, a mesma também pode ser compreendida de maneira objetivada e mecânica, podendo reforçar esta relação causal entre atividade física e saúde, na qual a saúde é uma meta a ser atingida e a atividade física torna-se o instrumento para tal fim, enquanto o ser humano é reduzido a objeto de aplicação de determinadas técnicas.

Essa divisão do conhecimento, do entendimento, reflete a divisão dentro do currículo dos próprios cursos. As disciplinas tratam cada segmento segundo seu entendimento, e poucas vezes essas visões são trazidas à reflexão de forma unificadora. Como resultado, encontram-se profissionais aderindo a modos de pensamentos sobre a atuação que, em sua maioria, não foram objetos de discussão e debate. As razões e consequências de se estudar sob determinado conjunto de disciplinas, muitas vezes, não são devidamente consideradas. Porém, conforme argumentam Nunes e Rúbio (2008), este sério debate sobre o currículo de um curso pode revelar anseios políticos preconizados pelas formas de poder dominantes, que, por sua vez, agem como pano de fundo na formação deste profissional visto que o conteúdo abordado e os temas lançados aos graduandos estão intimamente ligados ao modo como o mesmo virá a ser profissionalmente e contribuem também para a construção da identidade da própria área em questão. Neste mesmo estudo, a análise dos diversos currículos de educação física em consonância com o contexto político e social, revela como os interesses políticos nortearam a presença e a validação da técnica dentro dos contextos de formação do professor de educação física, visando educar o corpo e tornar o indivíduo, dentro do contexto hegemônico, socialmente aceitável.

O problema da identidade que também é discutido por diversos autores, tem aqui seu papel fundamental na discussão, uma vez que esta representação identitária penetra e influencia as tomadas de decisão e as compreensões daqueles que serão formados dentro da educação física. Segundo Crisório (2003), “o problema da identidade da educação física corresponde menos à dispersão de suas práticas do que com a alienação de seu saber, particularmente ao discurso da ciência." Este discurso irrefletido da ciência, como visto anteriormente, promove um pensamento reducionista de ser humano, distanciando assim as discussões das questões filosóficas, culturais e éticas e aproximando o conhecimento da técnica e da prescrição.

O conhecimento técnico da atividade física e do corpo conforta a aplicabilidade da mesma, uma vez baseada em conhecimentos científicos legitimados 
e legitimadores. Sendo assim configura-se uma impressão de que esses fatores são suficientes para pensar a atuação de um profissional da atividade física com o sujeito a quem se direciona a aplicação. A relação profissional baseada na aplicação de dado conhecimento desconsidera o sujeito destinatário como sendo também agente da ação como discutido por Carvalho (2001, p. 10):

O "lugar" destinado ao sujeito, ou o entendimento que prevalece a respeito do sujeito está caracterizado por uma "figura" que muitas vezes não pensa, não sente, não experimenta emoções, desejos, não carrega consigo sua própria história de vida. Freqüentemente ele aparece escondido em um grupo de sedentários ou praticantes de atividade física; em um grupo definido pela faixa etária (adulto, idoso); em um grupo definido pela natureza da atividade física que desenvolve; atleta, não-atleta; indivíduos sadios e doentes, entre outras conotações.

Corre-se o risco de considerar o aluno/atleta como depositório de informações, como se a maior ou menor absorção, evidenciada na quantidade, fosse refletir nos resultados do trabalho de um bom ou mau profissional. Esse ponto também pode sugerir que tendo sido transmitida a informação, a responsabilidade pela adesão, motivação ou continuidade da prática de atividade física, seja exclusivamente do aluno, e isenta o profissional de qualquer outra possibilidade de participação neste processo. E vai além, como põem em discussão Bagrichevsky e Estevão (2005, p. 67):

\begin{abstract}
Se por um lado é parcialmente aceitável a generalização de que há benefícios orgânicos decorrentes de algumas modalidades de exercício (se respeitados certos preceitos), por outro, esta argumentação torna-se discutível, na medida que pretende sustentar uma política conservadora, uma dimensão moral que responsabiliza cada pessoa por seu próprio adoecimento e desconsidera a dinâmica sistêmica e multifária que influencia os estados de enfermidade humana.
\end{abstract}

Essa ausência de responsabilidades na relação profissional é facilitada pela aplicação dos programas de atividade física como uma simples técnica, reduzindo a possibilidade de engajamento na relação aluno/professor, cliente/ profissional, agente de saúde/usuário. Torna, assim, a relação impessoal, a atividade física utilitária e o outro como objeto da aplicação. Compreendida na amplitude fenomenológica, a subjetividade abarca o conjunto desses elementos: propor uma atividade que não tenha seus sentidos esclarecidos pelo próprio sujeito é apenas utilizar uma técnica cegamente, alheia de iniciativa e 
perspectiva consistentes. A atividade física não é pura prática, é também aprendizado, é incluir na vida da pessoa algo novo, é transformação. É por conta desta complexidade que a atividade física não pode ser reduzida à técnica e à instrumentalização, deve ser algo constantemente sujeito às reflexões críticas acerca dos fundamentos, ações e consequências.

Diante disso, a saúde retorna aqui mais claramente na discussão uma vez que a atuação, amplamente considerada anteriormente, remete a esta grande área. Como vimos, a compreensão predominantemente biológica da atividade física e da própria saúde restringe a visão do próprio ser humano de maneira objetiva, o que faz perder a dimensão existencial tanto da prática como da própria saúde, o que é compartilhado por Barreira e Fernandes (2008, p. 5) para os quais: "se a orientação primeira das profissões de saúde era voltada ao aspecto físico do corpo, paciente objeto, problematizar a saúde de modo complexo reconduz essa orientação à dimensão existencial protagonizada pelas pessoas envolvidas no processo saúde doença.” Essa problematização da saúde é tomada aqui justamente como uma problematização da própria atuação na área da educação física. Sendo assim, o pensamento reflexivo traz para o campo de discussão um caminho que esclarece e fornece elementos que ajudem a re-pensar essa atuação. A reflexividade incentiva um constante olhar para a prática, para as atitudes tomadas, para novas formas de solucionar problemas. Pensar sobre isso induz a inclusão dos elementos que os resultados evidenciaram ser ignorados, mas que ajudam a dar sentido para a ação, pois a reflexão, como definida por Boud Koegh \& Walker (apud ANDERSON; KNOWLES; GILBOURNE, 2004, p. 191) "é uma atividade cognitiva que ajuda o sujeito a ligar o conhecimento profissional, a prática e a emergência do conhecimento em ação à consciência."

Um direcionamento da prática atento à reflexividade requer que o profissional assuma responsabilidades em relação ao sujeito, à atuação e à própria profissão (ANDERSON; KNOWLES; GILBOURNE, 2004, p. 196). Para assumir essas responsabilidades é preciso que durante a formação este profissional seja confrontado com formas de resolver problemas, pensar sobre soluções que impliquem cada caso em sua plenitude.

A graduação universitária é terreno fértil para praticar tais reflexões, principalmente os espaços destinados à prática, como nos estágios supervisionados. Essa supervisão pode seguir o caminho da orientação com um espaço destinado à reflexão: encerrar o potencial desse espaço na mera fiscalização de questões burocráticas e de comportamento protocolar, pouco ajuda o aluno a esclarecer sua própria atuação. Desta forma, não somente a atividade física, mas todos os 
aspectos que permeiam esse tema são tratados de maneira simplista e instrumental. A relação entre formação e atuação dá margem a reflexões:

Uma formação hegemonicamente experimental implicará numa atuação eminentemente técnica onde, assumida por dada e suficiente uma motivação para a prática de atividade física como a 'obtenção de saúde', sem muitos outros elementos, faz-se uso instrumental das ferramentas científicas com enfoque na destinação, a saúde tomada como fato corporal ou mental (BARREIRA; FERNANDES, 2008).

\section{CONCLUSÃO}

A conclusão deste trabalho se baseia na incansável tarefa de colocar em pauta discussões acerca da formação do profissional da área de atividade física e saúde. Por mais óbvio que possa parecer, formar uma pessoa que seja capaz de programar e gerir programas de atividade física que objetivam a melhora da saúde e qualidade de vida, de maneira restrita às relações de causa efeito, fundamentadas única e exclusivamente nas ciências naturais, é limitante no que se refere à realidade do ser humano uma vez que tais conhecimentos, ainda que de grande importância, não substituem e não contemplam a dimensão existencial do sujeito a quem essa atividade física se destina. Desta forma, o desafio é propor uma prática reflexiva que garanta o espaço deste sujeito enquanto agente deste processo. O processo, aqui destacado, permite que se contemple mais do que apenas finalidades e objetivos pré-determinados. O caminho para este objetivo e até a eventual mudança do mesmo faz parte da atuação, faz parte a elaboração conjunta de uma prática que tenha sentido e que este sentido possa ser compreendido por ambas as partes envolvidas. A responsabilidade do profissional é garantir que o aluno possa estar diante de uma prática que não se limite à técnica, pois a atividade física, muito mais que movimento é a expressão de um corpo, de uma corporeidade, de uma pessoa inserida numa sociedade, que vive, que tem sentimentos, história, emoções e reflexões. Tais elementos, por mais que possa parecer, não estão distantes da prática de uma atividade física. O sujeito é portador de valores, preocupações e desejos. Cabe ao profissional, não desvendar e nem mistificar esse ser humano, mas sim estar aberto para a compreensão do que ele, enquanto portador de todas essas dimensões, traz para esta relação. Desta forma têm-se a fenomenologia como método e atitude capaz de contribuir com a formação deste processo, por manter em aberto a reflexão em função de sua própria essência, que nunca dá por encerrada a compreensão de um fenômeno, mas segue na direção de desvelar constantemente como este 
se dá à consciência, ou seja, como é para o próprio sujeito a coisa em questão. $\mathrm{O}$ retorno às coisas mesmas, incluído no método fenomenológico, permite examinar de fato o fenômeno, suas consequências e as implicações da ação, o que contribui para um bom uso no sentido de respeitar e garantir a autonomia do ser humano envolvido neste processo.

A conclusão aqui segue atenta à importância da compreensão deste processo pelo profissional. Diante dos resultados obtidos, pode-se notar que raros são os momentos em que há uma reflexão acerca de sua própria ação. E que, em quase todos os relatos, por mais que de certa forma a reflexividade estivesse presente, a persistência e conclusão da mesma se ausentaram, cederam o passo à conclusão mecânica. Refletir de forma conclusiva, - e entende-se aqui conclusão não como um encerramento, mas como o alcance de algo racionalmente suficiente - é criar e esclarecer os significados de sua atuação, é se colocar nesta discussão. Problematizar a atuação é, num primeiro momento, questionar-se sobre sua própria escolha profissional, afinal é nesta escolha que se deposita dedicação e esforço por aquilo que encanta e dá sentido à vida. Se o contrário pode ser verdadeiro, então essa contrariedade deve começar justificando qual a ética de se viver a vida e a profissão de modo reprodutivo e irrefletido quando o acesso à mudança está à mão.

\section{REFERÊNCIAS}

ANDERSON, A G.; KNOWLES, Z.; GILBOURNE, D.. Reflective practice for Sport psychologists: concepts, models, practical implications and thoughts on dissemination. The Sport Psychologist, New Jersey, 18, p. 188203. 2004.

BAGRICHEVSKY, M.; ESTEVÃO, A.. Os sentidos da saúde e a Educação Física: apontamentos preliminares. Revista Arquivos em Movimento, Rio de Janeiro, v.1, n.1, p. 65-74. 2005.

BARREIRA, C. R. A.; FERNANDES, C. S. Corpo, ciência e saúde: excurso sobre as ciências humanas da atividade física. In: SEMINÁRIO NACIONAL SOCIEDADE, CORPO E CULTURA, 2008, Vitória. Seminário... 2008.

BARREIRA, C. R. A.; MASSIMI, M.. Arqueologia fenomenológica das culturas. Revista Online Estação Científica, Juiz de Fora, p. 1-11, 2005. 
BARREIRA, C. R. A. et al. A entrevista fenomenológica como instrumento da psicologia: metodologia e política de alteridade. In: SIMPÓSIO BRASILEIRO DE PSICOLOGIA POLÍTICA, 5., 2008, São Paulo. Anais... SBPP, 2008.

BRACHT, V. A constituição das teorias pedagógicas da educação física. Cadernos Cedes, Campinas, v. 19, n. 48, p. 69-87, 1999.

CAPRA, F. O ponto de mutação: a ciência, a sociedade e a cultura emergente. Trad. A. Cabral. São Paulo: Cultrix, 1995.

CARVALHO, Y. M. de. Atividade física e saúde: onde está e quem é o "sujeito" da relação? Revista Brasileira de Ciências do Esporte, São Paulo, v. 22, p. 9-21, 2001.

CARVALHO, Y. M. de. Saúde, sociedade e vida: um olhar da educação física. Revista Brasileira de Ciências do Esporte, Campinas, v. 3, p. 153168, 2006.

CARVALHO, Y. M. de. Educação física e saúde coletiva: uma introdução. In: LUZ, M. T. (Org.). Novos saberes e práticas em saúde coletiva: estudo sobre racionalidades médicas e atividades corporais. São Paulo: Hucitec, 2007. p. 19-34.

CRISORIO, R.. Educação física e identidade conhecimento, saber e verdade. Trad. W. Bracht. In: BRACHT, W.; CRISORIO, R. (Org.) A Educação física no Brasil e na Argentina: identidade, desafios e perspectivas. Campinas: Autores Associados, 2003.

FREIRE, P. Pedagogia da autonomia: saberes necessários à prática educativa. São Paulo: Paz e Terra, 2006.

GADAMER, H.. O caráter oculto da saúde. Trad. Antônio Luz Costa. Petrópolis: Vozes, 2006.

GORI, R.; DEL VOLGO, M.. Éxiles de l’intime: la médecine et la psychiatrie au service du nouvel ordre économique. Lonrai: Denoël, 2008.

MORIN, E.. Introdução ao pensamento complexo. Trad. Eliane Lisboa. Porto Alegre: Sulina, 2006 
NUNES, M. L. F.; RÚBIO, K. O(s) currículo(s) da educação física e a constituição da identidade de seus sujeitos. Currículo sem Fronteiras, Mangualde, Portugal, v. 8, n, 2, p. 55-77, 2008.

QUINT, F. O. et al. Reflexões sobre a inserção da educação física no Programa Saúde da Família. Motrivivência, Santa Catarina, n. 24, p. 81-95, 2005.

TRAVERSO-YÉPEZ, M. A interface psicologia social e saúde: perspectivas e desafios. Psicologia em Estudo, Maringá, v. 6, n. 2, p. 49-56, 2001.

\section{AGRADECIMENTOS}

Apoio: Programa Ensinar com Pesquisa - Pró-Reitoria de Graduação da Universidade de São Paulo 
